\title{
Thick-film gas sensors based on vanadium-titanium oxide powders prepared by sol-gel synthesis
}

\author{
Maria Cristina Carotta ${ }^{\mathrm{a}, *}$, Matteo Ferroni ${ }^{\mathrm{a}}$, Sandro Gherardi ${ }^{\mathrm{a}}$, Vincenzo Guidi ${ }^{\mathrm{a}}$, \\ Cesare Malagù ${ }^{\mathrm{a}}$, Giuliano Martinellia ${ }^{\mathrm{a}}$, Michele Sacerdoti ${ }^{\mathrm{b}}$, Maria Luisa Di Vona ${ }^{\mathrm{c}}$, \\ Silvia Licocciac ${ }^{\mathrm{c}}$, Enrico Traversa ${ }^{\mathrm{c}}$ \\ ${ }^{\mathrm{a}}$ INFM- Dipartimento di Fisica, Università di Ferrara, Via Paradiso 12, 44100 Ferrara, Italy \\ 'Dipartimento di Scienze della Terra, Università di Ferrara, Corso Ercole I D'Este 4, 44100 Ferrara, Italy \\ 'INSTM- Dipartimento di Scienze e Tecnologie Chimiche, Università di Roma "Tor Vergata", Via della Ricerca Scientifica, O0133 Rome, Italy
}

\begin{abstract}
Two titania powders modified by 10 at. $\%$ of vanadium were prepared by two different sol-gel routes. The powders fired at $650{ }^{\circ} \mathrm{C}$ had the rutile structure. These powders were used to produce prototype thick-film sensors. Four series of thick-film samples were fabricated by screen-printing, fired for $1 \mathrm{~h}$ at 650 and $850{ }^{\circ} \mathrm{C}$. The morphology and gas-sensing properties were examined and compared with those of pure and Ta-added titania films, previously studied by the authors. Ta addition inhibited the anatase-torutile phase transformation during heating and was also effective in keeping the $\mathrm{TiO}_{2}$ grain size in the nanometre range. On the contrary, $\mathrm{V}$ addition facilitated the anatase-to-rutile phase transformation. Thick films obtained from the two powders had similar conductance behaviour vs. temperature. The gas response of the films was affected by both the grain size and firing temperature.

(C) 2003 Elsevier Ltd. All rights reserved.
\end{abstract}

Keywords: Electrical properties; Gas sensors; Grain size; Sol-gel processes; $\mathrm{TiO}_{2}$

\section{Introduction}

The development of reliable and selective solid-state gas sensors has great importance both in the field of atmospheric pollution and in the emission control from combustion plants. Recently, many efforts have been aimed to improve the gas sensor performances. Improved selectivity has been obtained by addition of catalysts and/or dopants, ${ }^{1}$ while significant improvement of performance can be achieved by decreasing the particle size down to nanometre scale, thus obtaining an increased specific surface area. ${ }^{2}$

The synthesis of new materials is nowadays designed on the basis of previous experience and investigation. The results obtained by modifying titania with $\mathrm{Nb}$ and $\mathrm{Ta}^{3,4}$ suggested to us to investigate the effect of the addition to $\mathrm{TiO}_{2}$ of a few percentage of vanadium, which still has an extra valence $\left(\mathrm{V}^{5+}\right)$, while its ionic radius is smaller than that of $\mathrm{Ti}^{4+}$.

\footnotetext{
* Corresponding author.

E-mail address: carotta@fe.infn.it (M.C. Carotta).
}

Vanadium oxide supported over titanium dioxide is a mixed transition metal oxide with catalytic properties for several industrial applications. In particular, it has been shown that the mixture is effective in the selective catalytic reduction of nitrogen oxides with ammonia, ${ }^{5}$ as well as in the oxidation of $o$-xylene, ${ }^{6}$ alkylaromatics and of various organic substances, such as alkenes, toluene, methanol, etc. ${ }^{7}$

This work reports the preparation of vanadium-titanium oxide in thick-film form by screen printing technology for gas sensing applications. Such a technique allows the production of low-cost and robust chemical sensors with good reproducibility provided that the starting materials are very well controlled. ${ }^{8}$

Two different sol-gel procedures were used to synthesise the $\mathrm{V}$-added titania powders. The best results in terms of fine particle dimensions were obtained with the second route, consisting of a condensation in the presence of titanium halide.

The morphology of all V-added titania thick-film sensors was correlated with their electrical properties. The results were also compared with those obtained for 
pure and Ta-added titania films, previously studied by the authors. It was demonstrated that Ta addition inhibits the anatase-to-rutile phase transformation and is also effective in keeping the $\mathrm{TiO}_{2}$ grain size in nanometre range, thus allowing good gas responses. ${ }^{3}$ On the contrary, it was observed that the $\mathrm{V}$ addition facilitates the anatase-to-rutile transformation independently of the synthetic procedure.

\section{Experimental procedure}

V-added (10 at.\%) titania powders were prepared following two different sol-gel routes. In both cases vanadium(V)oxichloride was added to a solution previously made by diluting $\mathrm{Ti}(\mathrm{OiPr})_{4}$ in dichloromethane. To obtain the first powder (named TiV1) the dichloromethane was evaporated and a solution of $\mathrm{Ti}(\mathrm{OiPr})_{4}$ in ethanol was added to the residue. Adding a solution of ethanol/water 1:1 a gel was formed and then dried. The second powder (named TiV2) was obtained adding $\mathrm{TiCl}_{4}$ to the dichloromethane solution of $\mathrm{OVCl}_{3}$ and $\mathrm{Ti}(\mathrm{OiPr})_{4}$, evaporating the solvent, treating the residue with a solution of acetone/water, and then drying the resulting powder.

Simultaneous thermo-gravimetric and differential thermal analysis (TG/DTA) measurements, with a heating rate of $10^{\circ} \mathrm{C} / \mathrm{min}$ in air, were used to study the thermal decomposition behaviour of these precursors. According to the DTA results it was decided to calcine the TiV1 powder at $600{ }^{\circ} \mathrm{C}$ for $2 \mathrm{~h}$, and the TiV2 at $400{ }^{\circ} \mathrm{C}$ for $1 \mathrm{~h}$.

X-ray diffraction (XRD) analysis measurements were carried out using a Philips PW1830 vertical diffractometer with Bragg-Brentano geometry $\left(\mathrm{Cu}-K_{\alpha}\right.$ radiation, $40 \mathrm{kV}, 25 \mathrm{~mA}$ ), equipped with graphite monochromator.

Thick-film gas sensors were fabricated by screenprinting technology using the sol-gel processed titania-

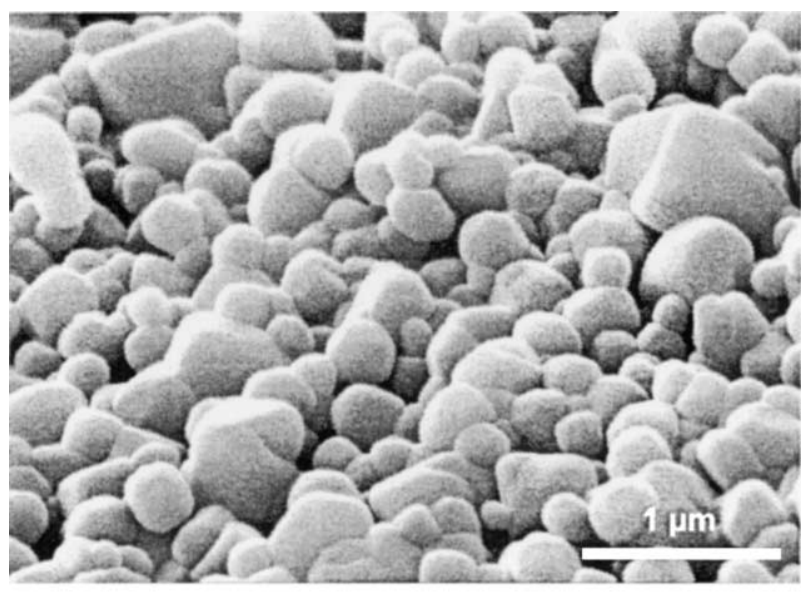

Fig. 1. SEM micrograph of the TiV1 sample fired at $650{ }^{\circ} \mathrm{C}$. based powders. The paste was prepared using a procedure reported elsewhere. ${ }^{8}$ The films were fired for $1 \mathrm{~h}$ at temperatures of 650 and $850{ }^{\circ} \mathrm{C}$. The thickness of the deposited layers was in the $20-40 \mu \mathrm{m}$ range.

The morphology of the powders and thick films was analysed by scanning electron microscopy (SEM).

Conductance measurements were performed in a sealed test chamber $\left(850 \mathrm{~cm}^{3}\right)$ with different test gases in dry air, at a flow rate of $0.51 / \mathrm{min}$. The operating temperature range was from 300 up to $450{ }^{\circ} \mathrm{C}$ and the test gases were $\mathrm{CO}(100 \mathrm{ppm}), \mathrm{C}_{6} \mathrm{H}_{6}(10 \mathrm{ppm})$, and $\mathrm{C}_{3} \mathrm{H}_{6}(100 \mathrm{ppm})$.

\section{Results and discussion}

SEM observations showed sensing layers made by a sequence of agglomerates of approximately $10 \mu \mathrm{m}$ in diameter, each of them consisting of particles with size depending on the synthetic procedure and firing temperature.

The TiV1 samples had larger grains than the TiV2 samples, at both firing temperatures of 650 and $850{ }^{\circ} \mathrm{C}$, the average particle diameter ranging from 330 to 480 $\mathrm{nm}$ for TiV1 samples and from 190 to $320 \mathrm{~nm}$ for TiV2 samples. Figs. 1 and 2 show the morphology of the TiV1 and TiV2 samples fired at $650{ }^{\circ} \mathrm{C}$, respectively. Increasing the firing temperature, the sintering process is enhanced causing the particles to coalesce. Compared with pure and $\mathrm{Nb}$ - or Ta-added titania layers, ${ }^{3,4}$ the morphology of the present samples suggests that the $\mathrm{V}$ addition aids the anatase-to-rutile phase transformation instead of hindering it. In fact, pure or Ta-added titania samples fired at $650{ }^{\circ} \mathrm{C}$ had anatase structure with particle dimensions ranging from 30 up to $50 \mathrm{~nm}$; after heating the samples up to $850{ }^{\circ} \mathrm{C}$, the pure titania samples had the rutile phase. Furthermore, heating the pure titania samples to $850{ }^{\circ} \mathrm{C}$ caused a large increase in the grain size up to about $400 \mathrm{~nm}$, whilst the same treatment

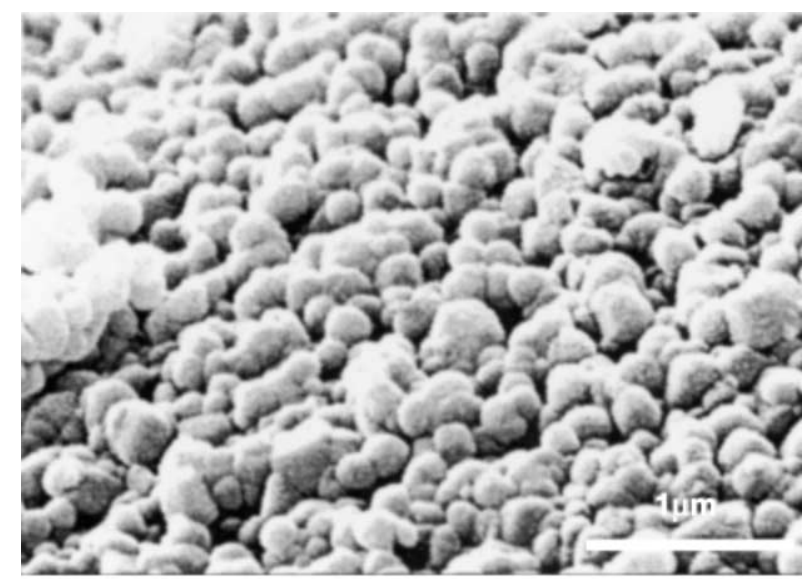

Fig. 2. SEM micrograph of the TiV2 sample fired at $650{ }^{\circ} \mathrm{C}$. 
performed on Ta-added titania gave very different results: the anatase phase was maintained and no significant increase in the particle dimension has been observed.

XRD results from the TiV1 and TiV2 powders heated to $650{ }^{\circ} \mathrm{C}$ confirmed the facilitating effect of $\mathrm{V}$-addition to the rutile structure and traces of $\mathrm{V}_{2} \mathrm{O}_{5}$ were also observed. XRD results from the TiV2 powders heated to 400 and $600{ }^{\circ} \mathrm{C}$ showed both the anatase and rutile phases. The different grain size obtained for the two series of films are probably due to different phase transition temperatures correlated with the synthetic procedures. Following the model proposed by Akhtar and coworkers, the extra-valence offered by $\mathrm{V}$, as well as by Ta and $\mathrm{Nb}$, should reduce the number of oxygen vacancies, thus retarding the phase transition ${ }^{9}$. On the contrary, we observed that such phase transition is favoured. This result can be explained by the fact that the ionic radius of $\mathrm{V}^{5+}$ is considerably smaller than that of $\mathrm{Ti}^{4+}$, thus presenting a lower hindrance to the cooperative movement of ions during the phase transformation.

Nevertheless, the extra-valence of vanadium is greatly effective in increasing the electrical conductance of both TiV1-650 and TiV2-650 samples. Fig. 3 compares the conductance as a function of inverse temperature of the TiV1-650 and TiV2-650 films with the conductance of pure and Ta-added titania samples fired at $650{ }^{\circ} \mathrm{C}$. The pure and Ta-added samples exhibit two region of conductivity indicating a non constant inter-grain barrier vs. temperature, while the V-added samples show a

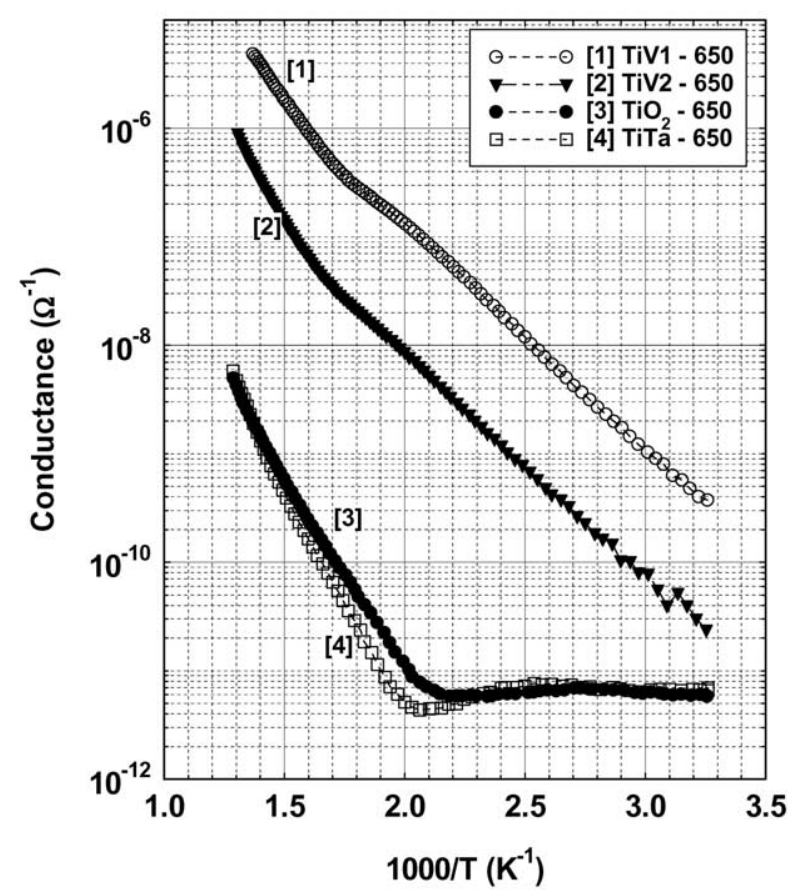

Fig. 3. Temperature-dependence of conductance in dry air of pure and Ta-added $\mathrm{TiO}_{2}$, and TiV1 and TiV2 samples fired at $650{ }^{\circ} \mathrm{C}$. conductance vs. temperature relation very close to a straight line (Fig. 3).

Fig. 4 shows the corresponding curves of the energy barrier as a function of temperature. The method used to obtain the curves in Fig. 4 is reported in Ref. 10. At low temperatures, pure and Ta-added samples display a strong linear increase of the energy barrier which stabilises the conductance from 100 up to above $200{ }^{\circ} \mathrm{C}$ (see Fig. 3). This means that the increasing amount of carriers yielded by temperature is compensated by the raise of the inter-grain surface potential barrier with increasing temperature.

$\mathrm{V}$-added titania films behave in a different way and the low values of the energy barrier reflect the high values of conductance. Moreover, the small difference between the minimum and maximum values of the energy barrier, particularly for the TiV1-650 sample, reflects the large amount of donor states caused by the extra-valence of vanadium. These phenomena indicate that these films should exhibit a poor performance as gas sensors. ${ }^{11}$

Fig. 5 shows the electrical response (given as the ratio between the conductance in gas, $G_{\text {gas }}$, and conductance in air, $G_{\text {air }}$ ) to $100 \mathrm{ppm}$ of propene in dry air (measured at $380{ }^{\circ} \mathrm{C}$ ) of all the $\mathrm{V}$-added films fired at 650 and $850{ }^{\circ} \mathrm{C}$ in comparison to the response of a pure $\mathrm{TiO}_{2}$ film fired at $650{ }^{\circ} \mathrm{C}$ and of a Ta-added film fired at $850{ }^{\circ} \mathrm{C}$. Surprisingly, the gas response of the samples fired at $650{ }^{\circ} \mathrm{C}$ are worst than those of the samples fired at $850{ }^{\circ} \mathrm{C}$, even though the grain size of the former films

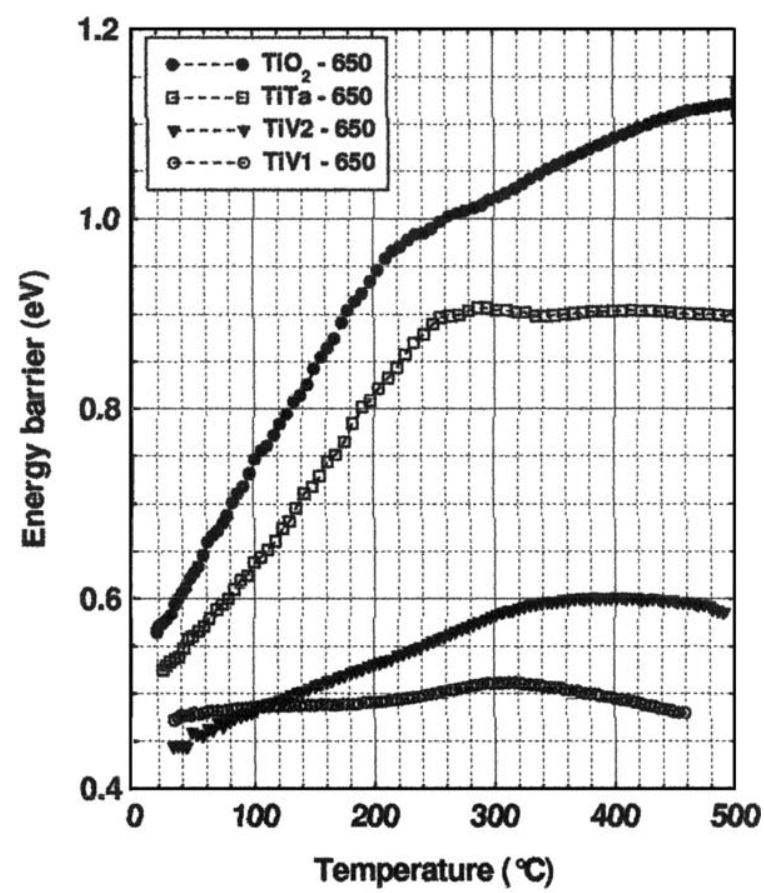

Fig. 4. Temperature-dependence of the barrier energy in dry air of pure and Ta-added $\mathrm{TiO}_{2}$, and TiV1 and TiV2 samples fired at $650{ }^{\circ} \mathrm{C}$. 


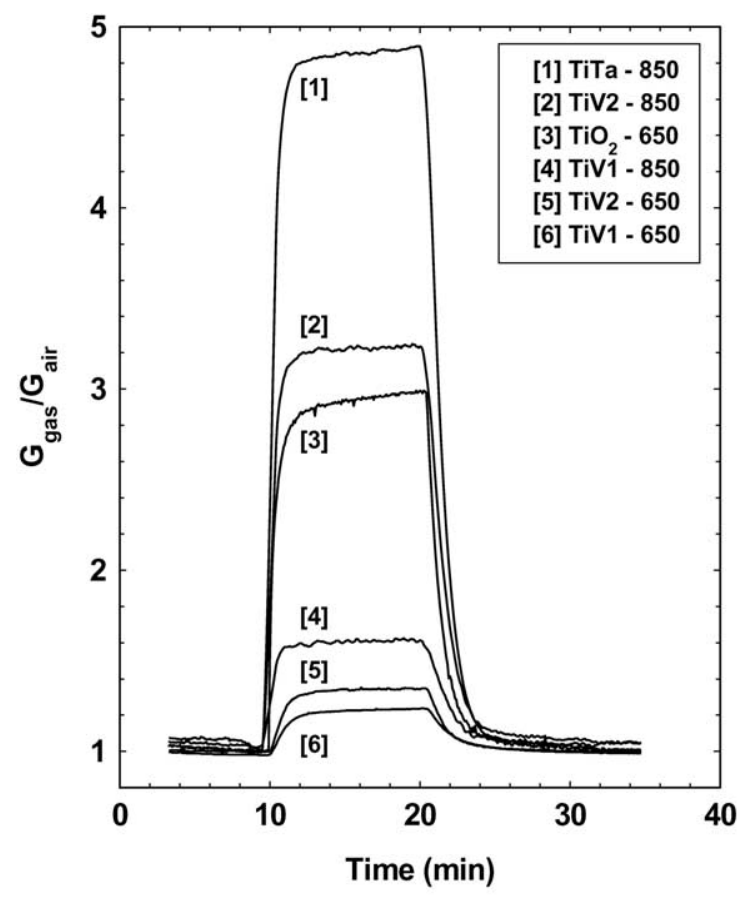

Fig. 5. Electrical response to propene $(100 \mathrm{ppm})$ in dry air at $350{ }^{\circ} \mathrm{C}$ of pure and Ta-added $\mathrm{TiO}_{2}$, and TiV1 and TiV2 samples fired at $650{ }^{\circ} \mathrm{C}$ and $/$ or $850{ }^{\circ} \mathrm{C}$.

was smaller. Actually, a similar behaviour was observed for the Ta-added samples, ${ }^{3}$ but in that case the microstructure of the two samples was the same. The $\mathrm{V}$-added samples do not have nano-sized grain and the samples fired at $850^{\circ} \mathrm{C}$ have a grain size twice the grain dimension of the films fired at $650{ }^{\circ} \mathrm{C}$. However, the gas response can be affected also by the presence of different surface states induced by the thermal treatments ${ }^{12}$ and/ or by catalytic additives as, for example, vanadium onto titania. Moreover, the lattice oxygen atoms can play also an important role in the detection mechanism and, therefore, further studies are needed to fully understand the effect. The TiV1-850 and TiV2-850 samples underwent the same electrical measurements shown in Figs. 3 and 4 , and it was found that, at the working temperature of $350{ }^{\circ} \mathrm{C}$, their conductance values were at least two orders of magnitude lower than those of the films fired at $650{ }^{\circ} \mathrm{C}$.

Measurements performed using carbon monoxide (100 ppm in dry air) and benzene (10 ppm in dry air) as test gases showed the same behaviour for all tested samples.

\section{Conclusions}

V-added titania powders were prepared using sol-gel procedures. Two different synthetic methods allowed to obtain powders (TiV1 and TiV2) homogeneously doped with vanadium and the method used to produce TiV2 powder gave the best results in terms of fine particle dimensions. Both syntheses produced V-added titania powders showing the phase transformation from anatase to rutile at temperatures lower than those observed for pure titania. It must be highlighted that the addition of $\mathrm{Nb}$ or Ta are causing, on the contrary, a hindrance for the phase transformation. Thick-film gas sensors were fabricated using screen-printing technology. Propene, benzene and carbon monoxide were used as test gases; it was always found that, in spite of their larger grain size, the samples fired at $850{ }^{\circ} \mathrm{C}$ were more sensitive than the films fired at $650{ }^{\circ} \mathrm{C}$. Such findings could be tentatively attributed to the catalytic properties of vanadium. Moreover, an evidence is obtained that the difference between the ionic radii is much more effective than the extra-valence of the additive to cause a hindrance to the anatase-to-rutile phase transformation in titania.

\section{Acknowledgements}

This work was partly supported by the Ministry of Education, University and Research (MIUR) of Italy. The authors wish to thank Ms. Cadia D'Ottavi (University of Rome Tor Vergata) for her valuable technical assistance.

\section{References}

1. Cabot, A., Vilà, A. and Morante, J. R., Analysis of the catalytic activity and electrical characteristics of different modified $\mathrm{SnO}_{2}$ layers for gas sensors. Sensors and Actuators B, 2002, 84, 12-20.

2. Martinelli, G., Carotta, M. C., Traversa, E. and Ghiotti, G., Thick film microsensors based on nano-sized semiconducting oxide powders. MRS Bulletin, 1999, 24(6), 30-36.

3. Traversa, E., Di Vona, M. L., Licoccia, S., Sacerdoti, M., Carotta, M. C., Crema, L. and Martinelli, G., Sol-gel processed $\mathrm{TiO}_{2}$-based nano-sized powders for use in thick-film gas sensors for atmospheric pollutant monitoring. Journal of Sol-Gel Science and Technology, 2001, 22, 167-179.

4. Carotta, M. C., Ferroni, M., Guidi, V. and Martinelli, G., Preparation and characterization of nanostructured titania thick films. Adv. Mater., 1999, 11, 943-946.

5. Burkardt, A., Weisweiler, W., van der Tillaart, J. A. A., SchäferSindlinger, A. and Lox, E. S., Influence of the $\mathrm{V}_{2} \mathrm{O}_{5}$ loading on the structure and activity of $\mathrm{V}_{2} \mathrm{O}_{5} / \mathrm{TiO}_{2} \mathrm{SCR}$ catalysts for vehicle application. Topics in Catalysis, 2001, 16/17, 369-375.

6. Grzybowska-Swierkosz, B., Vanadia-titania catalysts for oxidation of $o$-xylene and other hydrocarbons. Appl. Catal. A., 1997, 157, 263-310.

7. Centi, G., Nature of active layer in vanadium oxide and control of its reactivity in the selective oxidation and ammoxidation of alkylaromatics. Appl. Catal. A., 1996, 147, 267-298.

8. Guidi, V., Butturi, M. A., Carotta, M. C., Cavicchi, B., Ferroni, M., Malagù, C., Martinelli, G., Vincenzi, D., Sacerdoti, M. and Zen, M., Gas sensing through thick film technology. Sensors and Actuators B, 2002, 84, 72-77. 
9. Kamal Akhtar, M., Pratsinis, S. E. and Mastrangelo, S. V. R., Dopants in vapor-phase synthesis of titania powders. J. Am. Ceram. Soc., 1992, 75, 3408-3416.

10. Carotta, M. C., Dallara, C., Martinelli, G., Passari, L. and Camanzi, A., $\mathrm{CH}_{4}$ thick-film gas sensors: characterization method and theoretical explanation. Sensors and Actuators B, 1991, 3, 191-196.
11. Martinelli, G. and Carotta, M. C., Sensitivity to reducing gas as a function of energy barrier in $\mathrm{SnO}_{2}$ thick-film gas sensor. Sensors and Actuators, 1992, 7(1-3), 717-720.

12. Traversa, E., Villanti, S., Gusmano, G., Aono, H. and Sadaoka, Y., Design of ceramic materials for chemical sensors: $\mathrm{SmFeO}_{3}$ thick films sensitive to $\mathrm{NO}_{2}$. J. Am. Ceram. Soc., 1999, 82, 24422450 . 